\title{
A Comparison between Dietary Habits for Pregnant Women with Preterm and Term Delivery in Khorasan, Iran
}

\author{
Zohreh Teimouri' ${ }^{1}$ Mahrokh Dolatian ${ }^{2 *}$, Sara Shishehgar ${ }^{3}$, Marjan Ajami $^{4}$, \\ Hamid Alavi Majd ${ }^{5}$ \\ ${ }^{1}$ Department of Midwifery, International branch of ShahidBeheshti University of Medical Sciences, Tehran, Iran \\ ${ }^{2}$ Department of Midwifery, School of nursing and midwifery, Shahid Beheshti University of Medical Sciences, \\ Tehran, Iran \\ ${ }^{3}$ Faculty of Health, University of Technology, Sydney, Australia \\ ${ }^{4}$ Department of Nutrition Iran University of Medical Sciences, Tehran, Iran \\ ${ }^{5}$ Department of Biostatistics, School of Paramedical Sciences, Shahid Beheshti University of Medical Sciences, \\ Tehran, Iran \\ Email: zohre m teymuri@yahoo.com, ${ }^{*}$ mhdolatian@gmail.com, sara.shishehgar@uts.edu.au, \\ nutritionist80@gmail.com, alavimajd@gmail.com
}

Received 20 August 2015; accepted 18 September 2015; published 21 September 2015

Copyright (C) 2015 by authors and Scientific Research Publishing Inc.

This work is licensed under the Creative Commons Attribution International License (CC BY). http://creativecommons.org/licenses/by/4.0/

(c) (i) Open Access

\section{Abstract}

Background: Despite the advances in prenatal care and improving health indicators, preterm delivery and resultant infant mortality rate are still considerable. Emerged financial, social, mental and emotional damages could result in mental and behavioral disabilities for mothers as well as children. Although spontaneous preterm labor is well known as a multifactorial issue, yet poor nutrition is assumed as a strong related factor. Objective: To identify the role of dietary habits on preterm delivery prevalence in Iran, this study was conducted on pregnant women with preterm and term delivery. Methods: In this retrospective case-control study, 70 women with preterm labor and 70 women with term labor were compared in terms of their dietary habits. Women who met the inclusion criteria and referred to two hospitals in North-East of Iran were selected using purposive convenience sampling method and completed 163-item food frequency and dietary habits questionnaire. Results: This study showed that dietary habits of women with preterm labor are more unfavorable compared to women with term labor $(P=0.023)$. Generally, dietary habit of more than half of the women with preterm labor, in this study, was assessed unfavorable. In terms of different food groups, daily intake of vegetables was significantly lower in women with preterm labor $(P=\mathbf{0 . 0 2})$. Consumption of dairy products was also lower in women with preterm labor than

\footnotetext{
"Corresponding author.
}

How to cite this paper: Teimouri, Z., Dolatian, M., Shishehgar, S., Ajami, M. and Majd, H.A. (2015) A Comparison between Dietary Habits for Pregnant Women with Preterm and Term Delivery in Khorasan, Iran. Open Journal of Nursing, 5, $790-796$. http://dx.doi.org/10.4236/ojn.2015.59083 
women with term labor which was significant $(P=0.05)$. Conclusion: To prevent adverse outcomes of preterm delivery more attention regarding nutritional planning for pregnant women seems to be essential.

Keywords

Dietary Habit, Preterm Delivery, Pregnancy

\section{Introduction}

Despite the advances in prenatal care and improving health indicators, yet $5 \%-10 \%$ of all pregnancies are terminated as preterm, and prematurity is still the leading cause of neonatal mortality in developed and developing countries [1] [2]. Preterm infant is defined as the infant who is born before 37 completed weeks of pregnancy [3].

Prevalence of preterm delivery was estimated about 14.9 million globally. About $60 \%$ of this occurs in South Asia and sub-Saharan Africa, 18\% in African countries, 5\% in Europe and 11.1\% in the rest of the world [4]. Obviously, higher prevalence of spontaneous preterm labor occurs in poorest countries where people are assumed to be under-nourished [5]. Approximately, 57\% of neonatal death occurs at the first month of birth and $36 \%$ of them is attributable to preterm delivery [6]. Adverse outcomes of preterm delivery are considered as the greatest social and economic problems causing mental and behavioral disabilities [7].

Multiple pathologic processes such as length of cervix, preeclampsia and maternal stress may be associated with preterm delivery [8] [9] however poor nutrition is still assumed as a substantial related factor [10]-[12]. Based on literature, insufficient intake of food during pregnancy not only leads to increased risk of preterm delivery, fetal growth restriction and low birth weight [13]-[15], but also declined mother's health [15]. Nutritional needs increase during pregnancy due to the fetus growth, placenta, breast and uterus enlargement, increased body fat and blood volume [16]. Therefore, the quantity and quality of nutrition during pregnancy are of particular importance [15].

On the other hand, this is evident in a systematic review that food intake has no effect on preterm birth rate [17].

Since the impact of nutrition during pregnancy on preterm delivery is still controversial, we decided to investigate and compare the pregnant women's nutritional condition in two groups of preterm and term delivery.

\section{Methods and Materials}

Using a purposive convenience sampling method, 140 women who attended Social Security and Nohome Dey Hospitals and met inclusion criteria were recruited from October 2013 to October 2014. 70 participants were being hospitalized with a diagnosis of preterm delivery and 70 participants had term delivery. The proper sample size was estimated in consultation with a biological statistician (Equation (1): Correlation formula).

$$
n \geq 2 \frac{\left(z_{\alpha}+z_{\beta}\right)^{2} \sigma^{2}}{\left(\mu_{1}-\mu_{2}\right)^{2}}
$$

The study settings were public and referral hospitals located in a city in North-East of Iran.

Women who were between 18 and 35 years of age, Iranian, without any severe trauma or stress leading to preterm delivery were included in this study. They also should have no history of preterm labor and chronic diseases. The selected participants should not be smokers and medication recipients.

Data were collected through face to face interviews by the first author and each interview last about half an hour. Prior to each interview commencement, written consents collected followed by completion of the demographic and obstetric questionnaires. These data were collected after delivery and determining gestational age of the neonate (based on early pregnancy sonography and the neonate's appearance). Nutritional status of the women during recent 12 months was assessed by 168-item food-frequency questionnaire (168-FFQ). Ethics approval was obtained of Shahid Beheshti University and the study settings Ethics Committees. 
168-FFQ contains 168 food items with a standard serving size for each food product. The participants were asked to report their consumption frequency of each food product according to standard serving size. Depending on the type of food, the consumption frequency was asked and reported on daily, weekly, monthly and yearly basis. According to the Food Pyramid Guide, then, food items were placed in five major food groups (bread and cereal, vegetables, fruits, dairy, meat and beans).

Standard unit that was considered for daily use for each of the five major food groups was in accordance with the pregnancy nutrition guideline of the Health Ministry of Iran. Dietary habit was considered favorable if daily intake of food products in 4 - 5 main food groups was in accordance with the guideline. Otherwise, it was considered unfavorable. It means that women who intake daily 3 - 4 unit fruits, 7 - 10 units bread and cereals, 4 - 5 units vegetables, 3 - 4 units meat and beans and 3 - 4 units dairy were placed in favorable dietary group.

Validity of 168-FFQ has been determined in previous studies with Spearman coefficient mean of 0.80 [18] [19]. Moreover, reliability of that has been determined examined in previous studies $(r=0.59)$ [18].

Data analysis:

The collected data from each participant was statistically analyzed using Statistical Package for the Social Science version 22 (SPSS22). The descriptive statistics (frequency-percent, mean \pm SD) of Mann-Whitney, chisquare and t-test were used to analyze the collected data. Normal distribution was checked in consultation with a biological statistician. $\mathrm{P}<0.05$ was considered significant.

\section{Results}

In this study, participants had a mean age of $29 \pm 5.7$. Most participants, 90 (64.3\%), had education level less than diploma, 35 (25\%) diploma, and only 15 (10.7\%) had an academic education. 12 (8.6\%) of the participants' husbands were illiterate, 79 (56.4\%) less than diploma, 35 (25\%) diploma, and only 14 (10\%) had an academic education. Most women 130 (92.9\%) were house wives and 10 (7.1\%) were employed. Most of the participants in both groups, 86 (more than 60\%) were living in urban areas (Table 1). In addition, demographic characteristics of women in preterm and term delivery groups were compared using Chi-square test. Accordingly, there was no significant difference between two groups in terms of each character $(\mathrm{P}>0.05)$.

In terms of family income, $60 \%$ of women with preterm delivery and about half of women with term delivery (48.6\%) were categorized in low-income families. Mann-Whitney test showed that the difference between two groups in terms of family income was significant $(\mathrm{P}=0.05)$.

Regarding their obstetric characteristics $21.4 \%$ experienced their first pregnancy; nearly half (47.9\%) were in their second pregnancy; and 25\% were in third pregnancy. 36.5\% of participants had a history of abortion, $55.1 \%$ had intervals less than 4 years with their last pregnancy or abortion.

Respect to participants' BMI prior to pregnancy, there was a significant difference between two case and control groups $(\mathrm{P}=0.01)$. Women with lower BMI at the beginning of pregnancy had the higher possibility of preterm delivery (Table 2). Notably, about half of women in case group reported an unfavorable dietary habit during pregnancy.

Nutritional status in two case and control groups has been shown in Table 3. Evaluation of dietary habits in two groups showed that women with preterm delivery had more unfavorable dietary habits during pregnancy than women with term delivery $(\mathrm{P}=0.023)$.

Based on the Health Ministry guideline, daily intake of vegetables was less in women with preterm delivery than women in control group (Table 4). The results of chi-square test showed a significant difference between two groups in terms of daily intake of vegetables $(P=0.01)$. A significant difference also was recognized in terms of dairy intake in two groups $(\mathrm{P}=0.05)$ while bread, fruit, meat and beans consumption seems to not be different significantly in two groups $(\mathrm{P}>0.05)$.

Moreover, $60 \%$ and $50 \%$ of women with preterm and term delivery, respectively, intake 3 or less food groups on a daily basis. This was emerged from this study that about one third (32.9\%) of women in both groups intake only one food group. Notably, $4.3 \%$ of women in case group didn't consume food products according the guideline (Table 5).

\section{Discussion}

Unfavorable dietary habits were relatively sensible in women with preterm delivery. There are some studies that affirm this study's findings. In a study by Kamalifard et al. (2010), food consumption in term delivery group is 
Table 1. Demographic characters of participants.

\begin{tabular}{ccc}
\hline Age (year) & N (\%) & Mean \pm SD \\
\hline$<\mathbf{2 0}$ & $12(8.5)$ & 29.7 \\
$\mathbf{2 0}-\mathbf{2 4}$ & $46(32.8)$ & $31(22.3)$ \\
$\mathbf{2 5}-\mathbf{2 9}$ & $51(36.9)$ \\
$\mathbf{3 0}$ & \\
Education & $90(64.3)$ \\
Lower than Diploma & $35(25)$ \\
Diploma & $15(10.7)$ \\
Higher than Diploma & \\
Education (Husband) & $12(8.6)$ \\
No Education & $79(56.4)$ \\
Lower than Diploma & $35(25)$ \\
Diploma & $14(10)$ \\
Higher than Diploma & \\
Occupation & $130(92.9)$ \\
Housewives & $10(7.1)$ \\
Employed & \\
Monthly Income & $21(15)$ \\
<6,000,000 R & $55(39.3)$ \\
$\mathbf{6 , 0 0 0 , 0 0 0 ~ - ~ 9 , 0 0 0 , 0 0 0 ~ R ~}$ & $64(45.7)$ \\
$>\mathbf{9 , 0 0 0 , 0 0 0 ~ R ~}$ & \\
Residential Area & \\
City & $54(61.4)$ \\
Rural &
\end{tabular}

Table 2. Distribution of body mass index of participants.

\begin{tabular}{ccc}
\hline & & P-value \\
\hline Preterm & Body Mass Index before pregnancy & \\
$22 / 33 \pm 2 / 78$ & $23 / 34 \pm 2 / 09$ & $\mathrm{P}=0 / 01$ \\
\hline
\end{tabular}

Table 3. Comparison of dietary habits between two groups of preterm and term delivery.

\begin{tabular}{cccc}
\hline & & & \\
\cline { 2 - 4 } & Preterm & Delivery & P-value $^{1}$ \\
\hline Unfavorable & $45(64.3 \%)$ & $32(45.7 \%)$ & 0.023 \\
Favorable & $25(35.7 \%)$ & $38(54.3 \%)$ & \\
\hline
\end{tabular}

${ }^{1}$ The chi-square test was used.

Table 4. Comparison and frequency distribution of food groups' intake between two groups of preterm and term delivery.

\begin{tabular}{cccc}
\hline & \multicolumn{2}{c}{ Delivery } & P-value \\
\cline { 2 - 4 } food groups & Preterm & Term & 1.00 \\
Bread & $57(81.4)$ & $57(81.4)$ & 0.31 \\
Fruit & $33(47.1)$ & $39(55.7)$ & 0.01 \\
Vegetable & $26(37.1)$ & $40(57.1)$ & 0.05 \\
Dairy & $40(57.1)$ & $50(71.4)$ & 0.38 \\
Meat and beans & $47(67.1)$ & $42(60.0)$ & \\
\hline
\end{tabular}

The chi-square test was used 
Table 5. Comparison and frequency distribution of food intake between two groups of preterm and term delivery.

\begin{tabular}{|c|c|c|c|}
\hline \multirow{2}{*}{$\begin{array}{l}\text { Number of consumed food } \\
\text { groups }\end{array}$} & \multicolumn{2}{|c|}{ Delivery } & \multirow{2}{*}{ P-value } \\
\hline & Preterm & Term & \\
\hline None & $3(4.3)$ & 0 & \multirow{6}{*}{0.391} \\
\hline One case & 13 (18.6) & $10(14.3)$ & \\
\hline Two cases & $12(17.1)$ & 9 (12.9) & \\
\hline Three cases & $14(20.0)$ & $16(22.9)$ & \\
\hline Four cases & 16 (22.9) & 23 (32.9) & \\
\hline Five cases & $12(17.1)$ & $12(17.1)$ & \\
\hline
\end{tabular}

The chi-square test was used

more favorable than preterm delivery group [20]. Another study on women with twin pregnancies showed a significant relationship between appropriate nutrition along with regular prenatal care and decrease of preterm delivery prevalence [21].

About the importance of nutrition, it should be noted that the woman's body during pregnancy needs very various food products with adequate calories. Growth of the fetus, placenta, uterus and breasts and increasing the blood volume demand different food products especially protein. Lack of adequate and qualified nutrition causes health problems for the mother and fetus and considerably increases the risk of preterm delivery and resultant adverse outcomes for mothers and children [22] [23].

Comparison of daily intake of five major food groups indicated that vegetable intake was significantly lower in women with preterm delivery than other counterparts in term delivery group. This is well documented by previous studies that Mediterranean diet which is rich in fruits, vegetables, fish and olive oil could reduce the incidence of preterm delivery [24]-[26] due to antioxidants [27] by preventing the damaging effects of oxidative stress along with protection of the connective tissues and increase the strength of membranes [28]. So, concerning this fact that about half of preterm deliveries are resulted from premature rupture of membranes, consumption of vegetables should be of importance [29].

Awareness of the benefits of taking these food groups may increase the tendency to use them. Along with vegetables, milk and dairy consumption also seems to be of importance due to the influence of calcium deficiency on membrane permeability and uterus contractions that may contribute to preterm delivery [30].

Contrary to this study, Bakhtiari et al. (2007) concluded that the majority of pregnant women have relatively favorable dietary pattern during pregnancy [31]. However, others assessed pregnant women's dietary habits moderate and less than standard [32] [33]. This inconsistency may relate to the different regions of studies. The Bakhtiari's study was conducted in north of Iran where is green and rainy and food products are varied and affordable while this study was undertaken in an arid area where vegetables are expensive to afford.

According to the present study, the majority of women in case group had unfavorable dietary habits that can be attributable to their low socio-economic status and resultant low awareness of nutrition requirements during pregnancy [33]. This is documented that higher socio-economic status may improve pregnant women's health and decrease adverse effects of poor diet through increase the knowledge and life skills [34] although this study has found only a nearly significant relationship $(\mathrm{P}=0.08)$. However better dietary habits and term delivery could be attributable to higher socio-economic status [35]-[38], relationship is still controversial [20].

Having a higher BMI prior to pregnancy has a determining role in gestational age at the delivery time [39]. Inability to afford adequate food resources as a result of low socio-economic status may continue during pregnancy and contribute to restricted fetal growth and preterm delivery [40].

Generally, we expected to find some relationship between observing the daily intake of food groups and reduction of prevalence of preterm delivery. However we found this relationship, studies that confirm the current findings are still rare. Inconsistencies between the current study and Bakhtiari study in a same country [31] overshadow the results of both studies. So, further studies are worthwhile to cover limitations with this study. A limitation of this study is related to the memory of the participants. Since dietary habits were assessed by food frequency questionnaire for one year, the participants might not remember all the used food products. Another limitation is due to convenience sampling method. Further randomized control studies should be conducted to affirm the results of this study and make them generalizable to all Iranian pregnant women.

This study, however, was the first study conducted to explore relationship between dietary habits of pregnant women and prevalence of preterm delivery in Iran. 


\section{Acknowledgements}

This article is the result of a Master's Degree Dissertation in Midwifery from the International branch of Shahid Beheshti University of Medical Sciences We thank the staff of Tamin Ejtemaei and NohomDey Hospitals in Torbat Heidarieh and the women who participated in the study and answered the questionnaires.

\section{References}

[1] Karimi, R., Shabani, F., Dehghan Nayeri, N., Zareii, K., Khalili, G. and Chehrazi, M. (2012) Effect of Music Therapy on Physiological Pain Responses of Blood Sampling in Premature Infants. Hayat, 18, 76-86.

[2] Sangkomkamhang, U.S., Lumbiganon, P., Prasertcharoensook, W. and Laopaiboon, M. (2015) Antenatal Lower Genital Tract Infection Screening and Treatment Programs for Preventing Preterm Delivery. Cochrane Database of Systematic Reviews Issue, 2. http://dx.doi.org/10.1002/14651858.CD006178.pub3

[3] Bastek, J.A., Sammel, M.D., Srinivas, S.K., McShea, M.A., Foreman, M.N., Elovitz, M.A., et al. (2012) Clinical Prediction Rules for Preterm Birth in Patients Presenting with Preterm Labor. Obstetrics \& Gynecology, 119, 1119-1128. http://dx.doi.org/10.1097/AOG.0b013e31825503e5

[4] Blencowe, H., Cousens, S., Oestergaard, M.Z., Chou, D., Moller, A.-B., Narwal, R., et al. (2012) National, Regional, and Worldwide Estimates of Preterm Birth Rates in the Year 2010 with Time Trends since 1990 for Selected Countries: A Systematic Analysis and Implications. The Lancet, 379, 2162-2172. http://dx.doi.org/10.1016/S0140-6736(12)60820-4

[5] Beck, S., Wojdyla, D., Say, L., Betran, A.P., Merialdi, M., Requejo, J.H., et al. (2010) The Worldwide Incidence of Preterm Birth: A Systematic Review of Maternal Mortality and Morbidity. Bulletin of the World Health Organization, 88, 31-38. http://dx.doi.org/10.2471/BLT.08.062554

[6] Dorling, J.S. and Field, D.J. (2008) Value and Validity of Neonatal Disease Severity Scoring Systems. Archives of Disease in Childhood-Fetal and Neonatal Edition, 93, F80-F82.

[7] Newnham, C.A., Milgrom, J. and Skouteris, H. (2009) Effectiveness of a Modified Mother-Infant Transaction Program on Outcomes for Preterm Infants from 3 to 24 Months of Age. Infant Behavior and Development, 32, 17-26. http://dx.doi.org/10.1016/j.infbeh.2008.09.004

[8] Hestiantoro, A. (2013) Preterm Labor and Preeclampsia: Time to Make Good News. Indonesian Journal of Obstetrics and Gynecology, 36, 54.

[9] Shishehgar, S., Mahmoodi, A., Dolatian, M., Mahmoodi, Z., Bakhtiary, M. and Majd, H.A. (2013) The Relationship of Social Support and Quality of Life with the Level of Stress in Pregnant Women Using the PATH Model. Iranian Red Crescent Medical Journal, 15, 560-565. http://dx.doi.org/10.5812/ircmj.12174

[10] Muglia, L.J. and Katz, M. (2010) The Enigma of Spontaneous Preterm Birth. New England Journal of Medicine, 362, 529-535. http://dx.doi.org/10.1056/NEJMra0904308

[11] Plunkett, J. and Muglia, L.J. (2008) Genetic Contributions to Preterm Birth: Implications from Epidemiological and Genetic Association Studies. Annals of Medicine, 40, 167-179. http://dx.doi.org/10.1080/07853890701806181

[12] Goldenberg, R.L., Culhane, J.F., Iams, J.D. and Romero, R. (2008) Epidemiology and Causes of Preterm Birth. The Lancet, 371, 75-84. http://dx.doi.org/10.1016/S0140-6736(08)60074-4

[13] Rodríguez-Bernal, C.L., Rebagliato, M., Iñiguez, C., Vioque, J., Navarrete-Muñoz, E.M., Murcia, M., et al. (2010) Diet Quality in Early Pregnancy and Its Effects on Fetal Growth Outcomes: The Infancia y Medio Ambiente (Childhood and Environment) Mother and Child Cohort Study in Spain. The American Journal of Clinical Nutrition, 91, 16591666. http://dx.doi.org/10.3945/ajcn.2009.28866

[14] Rocco, P.L., Orbitello, B., Perini, L., Pera, V., Ciano, R.P. and Balestrieri, M. (2005) Effects of Pregnancy on Eating Attitudes and Disorders: A Prospective Study. Journal of Psychosomatic Research, 59, 175-179. http://dx.doi.org/10.1016/j.jpsychores.2005.03.002

[15] Delvarian-Zadeh, M., Bolbol Haghighi, N. and Ebrahimi, H. (2007) The Relationship between Nutritional Status of Mothers in Their Third Trimester and Delivery of Low Birth Weight Infants. Arak Medical University Journal, 10, 54-63.

[16] Fowles, E.R. (2004) Prenatal Nutrition and Birth Outcomes. Journal of Obstetric, Gynecologic, \& Neonatal Nursing, 33, 809-822. http://dx.doi.org/10.1177/0884217504270599

[17] Imdad, A. and Bhutta, Z.A. (2012) Maternal Nutrition and Birth Outcomes: Effect of Balanced Protein-Energy Supplementation. Paediatric and Perinatal Epidemiology, 26, 178-190. http://dx.doi.org/10.1111/j.1365-3016.2012.01308.x

[18] Haftenberger, M., Heuer, T., Heidemann, C., Kube, F., Krems, C. and Mensink, G. (2010) Relative Validation of a Food Frequency Questionnaire for National Health and Nutrition Monitoring. Nutrition Journal, 9, 36. http://dx.doi.org/10.1186/1475-2891-9-36 
[19] Mirmiran, P., Hosseini Esfahani, F., Mehrabi, Y., Hedayati, M. and Azizi, F. (2010) Reliability and Relative Validity of an FFQ for Nutrients in the Tehran Lipid and Glucose Study. Public Health Nutrition, 13, 654-662. http://dx.doi.org/10.1017/S1368980009991698

[20] Kamali Fard, M., Alizadeh, R., Sehati Shafaei, F. and Gojazadeh, M. (2010) The Effect of Lifestyle on the Rate of Preterm Birth. Journal of Ardabil University of Medical Sciences, 10, 55-63.

[21] Luke, B., Brown, M.B., Misiunas, R., Anderson, E., Nugent, C., van de Ven, C., et al. (2003) Specialized Prenatal Care and Maternal and Infant Outcomes in Twin Pregnancy. American Journal of Obstetrics and Gynecology, 189, 934-938.

[22] Khatun, S. and Rahman, M. (2008) Socio-Economic Determinants of Low Birth Weight in Bangladesh: A Multivariate Approach. Bangladesh Medical Research Council Bulletin, 34, 81-86.

[23] Burris, H.H., Mitchell, A.A. and Werler, M.M. (2010) Periconceptional Multivitamin Use and Infant Birth Weight Disparities. Annals of Epidemiology, 20, 233-240. http://dx.doi.org/10.1016/j.annepidem.2009.12.003

[24] Haugen, M., Margrete Meltzer, H., Lise Brantsæter, A., Mikkelsen, T., Louise Østerdal, M., Alexander, J., et al. (2008) Mediterranean-Type Diet and Risk of Preterm Birth among Women in the Norwegian Mother and Child Cohort Study (MoBa): A Prospective Cohort Study. Acta Obstetricia et Gynecologica Scandinavica, 87, 319-324. http://dx.doi.org/10.1080/00016340801899123

[25] Khoury, J., Henriksen, T., Christophersen, B. and Tonstad, S. (2005) Effect of a Cholesterol-Lowering Diet on Maternal, Cord, and Neonatal Lipids, and Pregnancy Outcome: A Randomized Clinical Trial. American Journal of Obstetrics and Gynecology, 193, 1292-1301. http://dx.doi.org/10.1016/j.ajog.2005.05.016

[26] Haggarty, P., Campbell, D.M., Duthie, S., Andrews, K., Hoad, G., Piyathilake, C., et al. (2009) Diet and Deprivation in Pregnancy. British Journal of Nutrition, 102, 1487-1497. http://dx.doi.org/10.1017/S0007114509990444

[27] Loy, S.-L., Marhazlina, M., Nor Azwany, Y. and Hamid Jan, J. (2011) Higher Intake of Fruits and Vegetables in Pregnancy Is Associated with Birth Size. Southeast Asian Journal of Tropical Medicine and Public Health, 42, 1214-1223.

[28] Siega-Riz, A.M., Promislow, J.H., Savitz, D.A., Thorp, J.M. and McDonald, T. (2003) Vitamin C Intake and the Risk of Preterm Delivery. American Journal of Obstetrics and Gynecology, 189, 519-525. http://dx.doi.org/10.1067/S0002-9378(03)00363-6

[29] Abedini, Z. and Gaini, M. (2011) Dietary Food Intake of Pregnant Women Based on Food Guide Pyramid and Its Related Factors. Iran Journal of Nursing, 24, 36-46.

[30] Mahmoodi, Z., Karimlou, M., Sajjadi, H., Dejman, M. and Vameghi, M. (2013) Development of Mother's Lifestyle Scale during Pregnancy with an Approach to Social Determinants of Health. Global Journal of Health Science, 5, 208-219. http://dx.doi.org/10.5539/gjhs.v5n3p208

[31] Bakhtiari, A., Sajadi, P. and Hajian, K. (2007) Nutrient Consumption Pattern in Pregnant Women Referred to Health Care Centers in Babol.

[32] Fadakar Soogheh, K., Ghav, A., Niknami, M. and Kazemnejad Leili, E. (2012) Relationship between Mothers’ Nutritional Status and Weight Gain during Pregnancy with Low Birth Weight. Journal of Guilan University of Medical Sciences, 21, 27-35.

[33] Shaikh, F., Zeeshan, F., Hakeem, R., Basit, A., Fawwad, A. and Hussain, A. (2014) Maternal Dietary Intake and Anthropometric Measurements of Newborn at Birth. The Open Diabetes Journal, 7, 14-19. http://dx.doi.org/10.2174/1876524601407010014

[34] Adler, N.E. and Newman, K. (2002) Socioeconomic Disparities in Health: Pathways and Policies. Health Affairs, 21, 60-76. http://dx.doi.org/10.1377/hlthaff.21.2.60

[35] Dolatian, M., Mirabzadeh, A., Forouzan, A.S., Sajjadi, H., Majd, H.A. and Moafi, F. (2012) Preterm Delivery and Psycho-Social Determinants of Health Based on World Health Organization Model in Iran: A Narrative Review. Global Journal of Health Science, 5, 52-64. http://dx.doi.org/10.5539/gjhs.v5n1p52

[36] Park, M.-J., Son, M., Kim, Y.-J. and Paek, D. (2013) Social Inequality in Birth Outcomes in Korea, 1995-2008. Journal of Korean Medical Science, 28, 25-35. http://dx.doi.org/10.3346/jkms.2013.28.1.25

[37] Moster, D., Lie, R.T. and Markestad, T. (2008) Long-Term Medical and Social Consequences of Preterm Birth. New England Journal of Medicine, 359, 262-273. http://dx.doi.org/10.1056/NEJMoa0706475

[38] Zarbakhsh Bhari, M.R., Hoseinian, S., Afrooz, G. and Hooman, H. (2012) The Comparison of Many Biological Characteristics, Economical Conditions, General Health (Mental), of Mothers with Low and Normal Birth Weight at Guilan Province. Payavard Salamat, 5, 67-78.

[39] Sukalich, S., Mingione, M.J. and Glantz, J.C. (2006) Obstetric Outcomes in Overweight and Obese Adolescents. American Journal of Obstetrics and Gynecology, 195, 851-855. http://dx.doi.org/10.1016/j.ajog.2006.06.070

[40] Viengsakhone, L., Yoshida, Y. and Sakamoto, J. (2010) Factors Affecting Low Birth Weight at Four Central Hospitals in Vientiane, Lao PDR. Nagoya Journal of Medical Science, 72, 51-58. 